\title{
Effect of Discontinuous Change in Cooling Rate during Continuous \\ Cooling on Pearlitic Transformation Behavior of Steel ${ }^{*}$
}

\section{By Nobuyoshi SHIMIZU** and Imao TAMURA**}

\section{Synopsis}

In this investigation, the pearlitic transformation behavior of steel with cooling rates discontinuously altered during continuous cooling was studied in relation to the CCT diagram of the steel. The main results are as follows:

(1) The pearlitic transformation behavior with cooling rates discontimuously altered during continuous cooling was different from that given by a usual CCT diagram.

(2) The pearlitic transformation behavior and the critical cooling rate with the cooling rate altered at a point during continuous cooling were observed to be related to the incubation period consumed before changing the cooling rate.

(3) Including the degree of consumed incubation period in usual CCT diagram as a parameter, the transformation behavior and the critical cooling rate could be estimated from a conventional CCT diagram.

(4) If the same amount of the incubation period was consumed by either continuous cooling or isothermal holding, the transformation behavior was virtually the same in the subsequent cooling when the cooling started from the same temperature.

\section{Introduction}

The continuous cooling transformation diagram (hereinafter called CCT diagram) represents the transformation behavior of steel during cooling at various cooling rates, by means of a group of cooling curves having the same shape. The CCT diagram were mostly determined by Newtonian or linear cooling without any discontinuous change in the cooling rate. ${ }^{1-7)}$ In practical heat treatment operations, however, there are many cases where the cooling rates are altered discontinuously during the cooling. In oil quenching, for example, there are remarkable changes in the cooling rate at each stage of the vapor blanket, boiling and convection. Such a change of cooling rate during cooling must cause different types of transformation behavior from those shown by the CCT diagram obtained by the cooling without any discontinuous change of the rate. The change in transformation behavior with that in the cooling rate depends mainly on the difference in the consumption of incubation period below the equilibrium transformation temperature.

In this investigation, the consumption process of incubation period was considered and a method of perceiving the transformation behavior in such cases of the discontinuous change in cooling by using a usual CCT diagram was examined.

\section{Some Considerations on Consumption of In- cubation Period}

As is already well known, ${ }^{8)}$ if the cooling curve
$A_{1}-X(T)$ is divided into a number of stages of $\Delta t_{1}$, $\Delta t_{2}, \ldots$ and $\Delta t_{n}$ at $T_{1}, T_{2}, \ldots$ and $T_{n}$, respectively, and if isothermal incubation periods at $T_{1}, T_{2}, \ldots$ and $T_{n}$ are defined as $Z_{1}, Z_{2}, \ldots$ and $Z_{n}$, respectively as shown in Fig. 1, the consumption of incubation period (I.P.) during cooling from $A_{1}$ to $T_{n}$ is shown as

$$
\text { I.P. }\left(T_{n}\right)=\frac{\Delta t_{1}}{Z_{1}}+\frac{\Delta t_{2}}{Z_{2}}+\cdots+\frac{\Delta t_{n}}{Z_{n}}=\sum_{t=0}^{t=t_{n}} \frac{\Delta t(T)}{Z(T)}
$$

If each stage is getting close into infinitesimal,

$$
\operatorname{I.P} .\left(T_{n}\right)=\int_{t=0}^{t=t_{n}} \frac{d t}{Z(T)}=\int_{A_{1}}^{T_{n}} \frac{d t / d T}{Z(T)} d T
$$

where, $A_{1}$ is the equilibrium transformation temperature.

When the cooling rate is constant $\left(\alpha^{\circ} \mathrm{C} / \mathrm{sec}\right)$,

$$
\text { I.P. }\left(\mathcal{T}_{n}\right)=\frac{1}{\alpha} \int_{A_{1}}^{T_{n}} \frac{d T}{Z(T)}
$$

At the temperature where I.P. $=1$, the transformation will start.

When the specimen is cooled at a constant rate of $\alpha$ from $A_{1}$ to $P$ and the rate is discontinuously altered at $P$ to another constant rate of $\beta$ as shown in Fig. 2, the transformation starts at $E$ where the following equation is satisfied.

$$
\frac{1}{\alpha} \int_{A_{1}}^{T_{P}} \frac{d T}{Z(T)}+\frac{1}{\beta} \int_{P}^{T_{E}} \frac{d T}{Z(T)}=1
$$
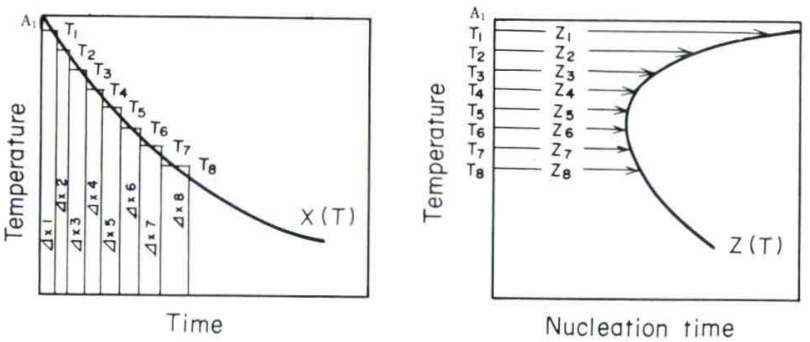

$\Delta X_{1}, \Delta X_{2}$, etc.: infinitesimal subdivisions of cooling time

$T_{1}, T_{2}$, etc.: temperature to be held for $\Delta X_{1}, \Delta X_{2}$, etc., respectively

$Z_{1}, Z_{2}$, etc.: nucleation time corresponding to $T_{1}, T_{2}$, etc., respectively

Fig. 1. Schematic diagram showing how incubation period is consumed during continuous cooling $(X(\mathcal{T}))^{10)}$

* Originally published in Tetsu-to-Hagané, 61 (1975), 2375, in Japanese. English version received November 1 , 1976.

** Koyo Netsushori Co., Ltd., Takochi, Yao-shi, Osaka 581.

*** Faculty of Engineering, Kyoto University, Yoshida-Honmachi, Sakyo-ku, Kyoto 606. 
In Figs. 3 and 4 are schematically shown the lines where the transformation starts when such discontinuous change in the cooling rate occurs under various conditions of continuous cooling. In Fig. 3 (a) the cooling rate is altered into several rates at a temperature $\mathcal{T}_{P}$ during cooling at a constant rate of $\alpha$ smaller than the critical cooling rate $(\gamma)$. The transformation start line is illustrated by $R^{\prime}-F$. Figure 3 (b) shows the case where $\alpha$ is equal to $\gamma$ and Fig. 3 (c) is for the case where $\alpha$ is larger than $\gamma$.

The consumption of incubation period from $A_{1}$ to $R$ at the critical cooling rate of $\gamma$,

$$
\frac{1}{\gamma} \int_{A_{1}}^{T_{R}} \frac{d T}{T(T)}=1
$$$$
\text { Hence, } \quad \gamma=\int_{A_{1}}^{T_{R}} d T(T)
$$

and from Eq. (4),

$$
\frac{1}{\alpha} \int_{A_{1}}^{T_{P}} \frac{d T}{Z(T)}+\frac{1}{\delta} \int_{T_{P}}^{T_{R}} \frac{d T}{Z(T)}=1
$$

The critical cooling rate $\delta$ from $P$ is higher than $\gamma$ when $\alpha<\gamma$, and is lower than $\gamma$ when $\alpha>\gamma$. Figure 4 shows start lines of transformation in several cases where the cooling rate is discontinuously altered into

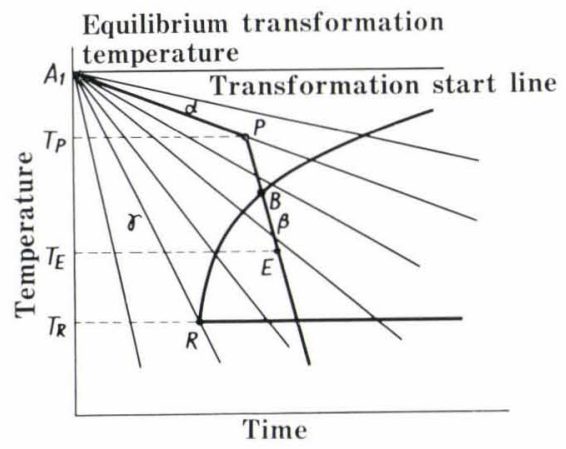

Fig. 2. Schematic illustration of CCT diagram and cooling curve
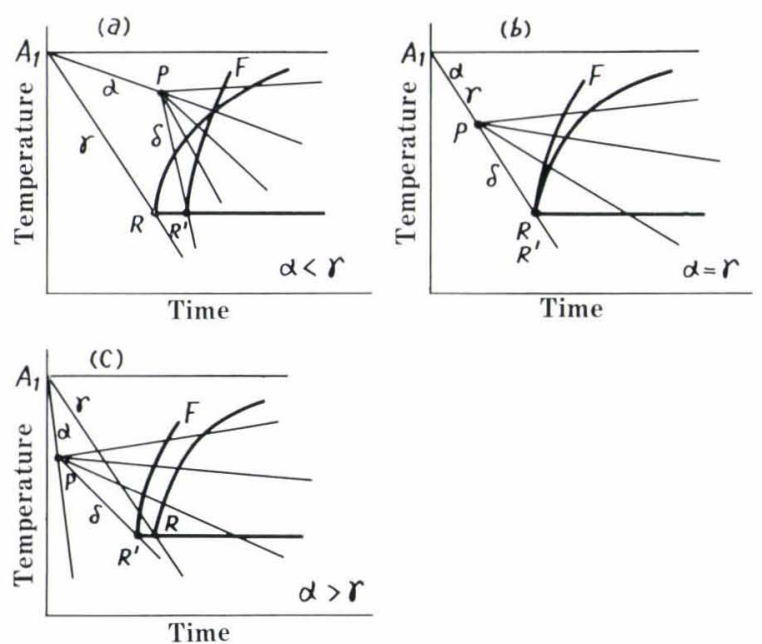

Fig. 3. Schematic illustration of transformation behavior when cooling rate was altered at $P$ $\beta$ at several points during cooling at the rate of $\alpha$; (a) $\gamma>\alpha>\beta$, (b) $\gamma>\beta>\alpha$, (c) $\gamma=\beta>\alpha$, (d) $\beta>\gamma>\alpha$, (e) $\gamma=\alpha>\beta$, and (f) $\alpha>\gamma>\beta$.

An inverse quench hardening ${ }^{9)}$ is sometimes observed when the specimen is quenched into oil having a long vapor blanket stage, or when it is held in air for some period before rapid quenching. In these cases, some of the incubation period is consumed at the surface of the specimen, while it is not at the center, as shown in Fig. 5; this causes the inverse quench hardening.
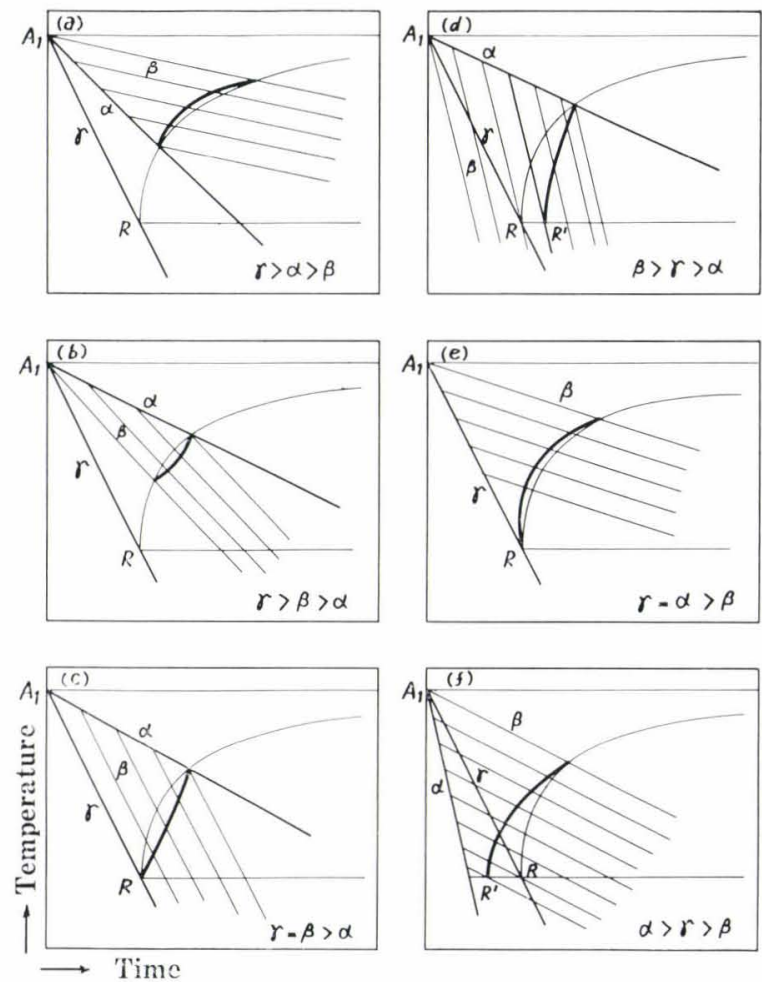

Fig. 4. Schematic illustration of transformation behavior when cooling rate was altered from $\alpha$ to $\beta$

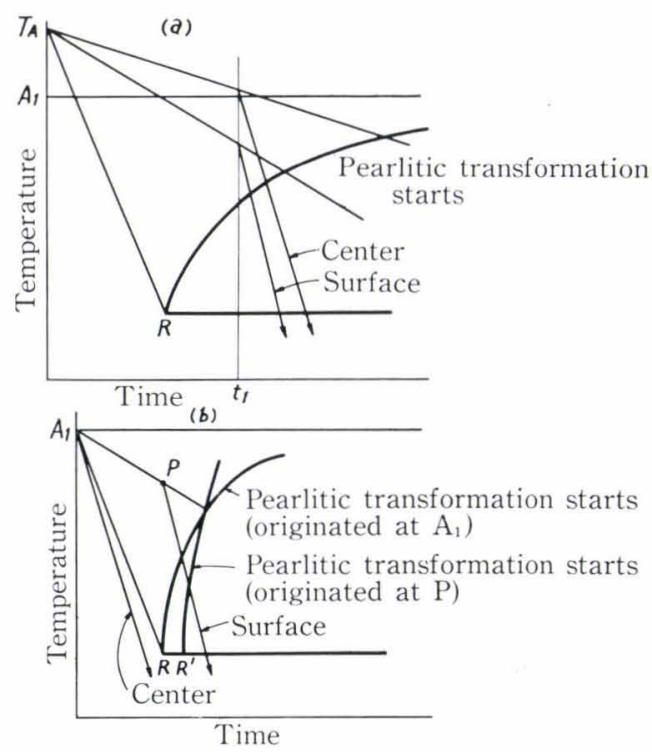

Fig. 5. Schematic illustration of inverse quench-hardening 


\section{Specimens and Experimental Procedure}

The chemical composition of the steel used JIS SUJ 2 is shown in Table 1. The specimen having a diameter of $5.2 \mathrm{~mm}$ was subjected to spheroidizing annealing. For changing the cooling rate, cylindrical sheaths of a stainless steel (JIS SUS 304) having various thickness $(0.8$ to $11.3 \mathrm{~mm})$ were employed to surround the specimen, so that the specimen could be cooled at different rates depending on the thickness of the sheath. The inside diameter of the sheath was $5.4 \mathrm{~mm}$, and the specimen was inserted therein. After being austenitized at $1050^{\circ} \mathrm{C}$ for $15 \mathrm{~min}$ in charcoal in order to prevent decarburizing, the specimen with a sheath was air-cooled and taken out from the sheath at various temperatures in the course of cooling and immediately quenched into $5 \%$ brine so as to freeze the structure. Then, the amount of transformation was determined by the measurement of hardness $\left(H_{R} C\right)$ and by microscopic observation. By repeating these operations at various cooling rates, the CCT diagram of the steel could be determined. The high austenitizing temperature was adoped for the purpose of preventing bainitic transformation during cooling.* As the etching solution for the observation of the structure, $5 \%$ nital was used.

The transformation behavior during cooling in which the cooling rate discontinuously changed was examined. After austenitized under the same condition, the specimen was air-cooled in a double sheath comprising an inner sheath of $8 \mathrm{~mm} \phi$ and an outer sheath of a larger diameter, and taken out at various temperatures in the process of cooling from both the sheaths or together with the inner one from the outer sheath only, and air-cooled successively to room temperature. Then, the transformation behavior was examined by the measurement of the hardness and observation of the structure. The cooling curves were recorded by means of a pen-writing recorder (oscillograph) to which was connected a thermocouple of $1 \mathrm{~mm} \phi$ with a protective sheath of JIS SUS $310 \mathrm{~S}$ inserted into the center of the specimen.

The TTT diagram was then determined. Immediately after austenitizing under the same condition as above, the specimen was directly quenched into a lead bath at various temperatures and held isothermally for various periods. After that, the specimen was completely quenched into $5 \%$ brine to

Table 1. Chemical compositions of steel used (wt \%)

\begin{tabular}{cccccccc}
\hline $\mathrm{C}$ & $\mathrm{Si}$ & $\mathrm{Mn}$ & $\mathrm{P}$ & $\mathrm{S}$ & $\mathrm{Cr}$ & $\mathrm{Cu}$ & $\mathrm{Ni}$ \\
\hline 1.05 & 0.27 & 0.40 & 0.017 & 0.009 & 1.46 & 0.08 & 0.05
\end{tabular}

freeze the structure.

Further, for the purpose of examining the transformation behavior occurring during cooling after consumption of a fraction of the incubation period by isothermal holding, the specimen was taken out from the lead bath midway in the process of incubation-period consumption, and was air-cooled. The transformation behavior of this specimen was determined, and its relation to the CCT diagram was investigated.

\section{Experimental Results and Discussion}

\section{Transformation Behavior after Discontinuous Change in Cooling Rate during Cooling}

\section{Continuous Cooling Transformation Diagram}

The CCT diagram** of the specimen (JIS SUJ 2, austenitized at $1050^{\circ} \mathrm{C}$ for $15 \mathrm{~min}$ ) was determined as shown in Fig. 6 (a). While the specimen is cooled at a constant rate from the austenitizing temperature $\left(T_{A}\right)$, the cooling rate is slowed down due to the pearlitic transformation, and returns to the original rate after the transformation. In this work, however, the figures are drawn in a manner so simplified as if the cooling continues at the same rate as that before the start of transformation, as shown in Fig. 6 (b). Therefore, Fig. 6 (b) is a modified CGT diagram. The hardness $\left(H_{R} C\right)$ and the amount of pearlitic transformation are illustrated in the figures.

From Fig. 6, the critical cooling rate is found as $9.7^{\circ} \mathrm{C} / \mathrm{sec}$. The hardness of a specimen quenched at a higher rate than the critical cooling rate shows a little lower value*** due to retained austenite.

\section{Transformation Behavior When Coonlig Rate is Changed during Cooling}

In Fig. 7, when the specimen is cooled at a rate of $3.4^{\circ} \mathrm{C} / \mathrm{sec}$ from $T_{A}$, the transformation starts at the point $E$ and is completed at the point $T_{X}$. The hardness in this case was $H_{R} C 41.5$ after the specimen was cooled to room temperature, and the composition of the structure was $100 \%$ pearlite. On the other hand, if the cooling rate is changed to $9.7^{\circ} \mathrm{C}$ / sec at the point $A, B, C, D, E$ or $F$ on the cooling at the rate of $3.4^{\circ} \mathrm{C} / \mathrm{sec}$, the cooling thereafter proceeds as shown by the dotted lines. The hardnesses in these cases are shown by the numerals in circles at the ends of dotted lines. For example, if the rate is changed to $9.7^{\circ} \mathrm{C} / \sec$ at the point $D$ on the cooling line, the hardness obtained is $H_{R} C 56$. Thus, the change in cooling rate during cooling results in a transformation behavior different from that shown by the CCT diagram without any change in cooling rate.

* In the CCT diagram of SUJ 2,10) bainitic transformation can be observed in the process of cooling when the austenitizing temperature is $860^{\circ} \mathrm{C}$, but if the austenitizing temperature is as high as $1050^{\circ} \mathrm{C}$, it cannot be seen. This is also understood from the fact that in the TTT diagram with the austenitizing temperature of $1050^{\circ} \mathrm{C}$, the incubation period of bainite is extremely prolonged in comparison with that of pearlite. By the way, the average diameter of carbide particles in the spheroidized specimen was $0.5 \mu$, and after austenitized at $1050^{\circ} \mathrm{C}$, the carbide was completely in solid solution of austenite.

** The abscissa of CCT diagram is illustrated by a proportional time-scale here, while it is usually shown by a logarithmic scale.

*** In continuous cooling, a precipitation of carbide occurs before the pearlitic transformation starts. ${ }^{10)}$ Though the precipitation of carbide was also recognized in this work at grain boundaries, it had a negligible effect on this study. 


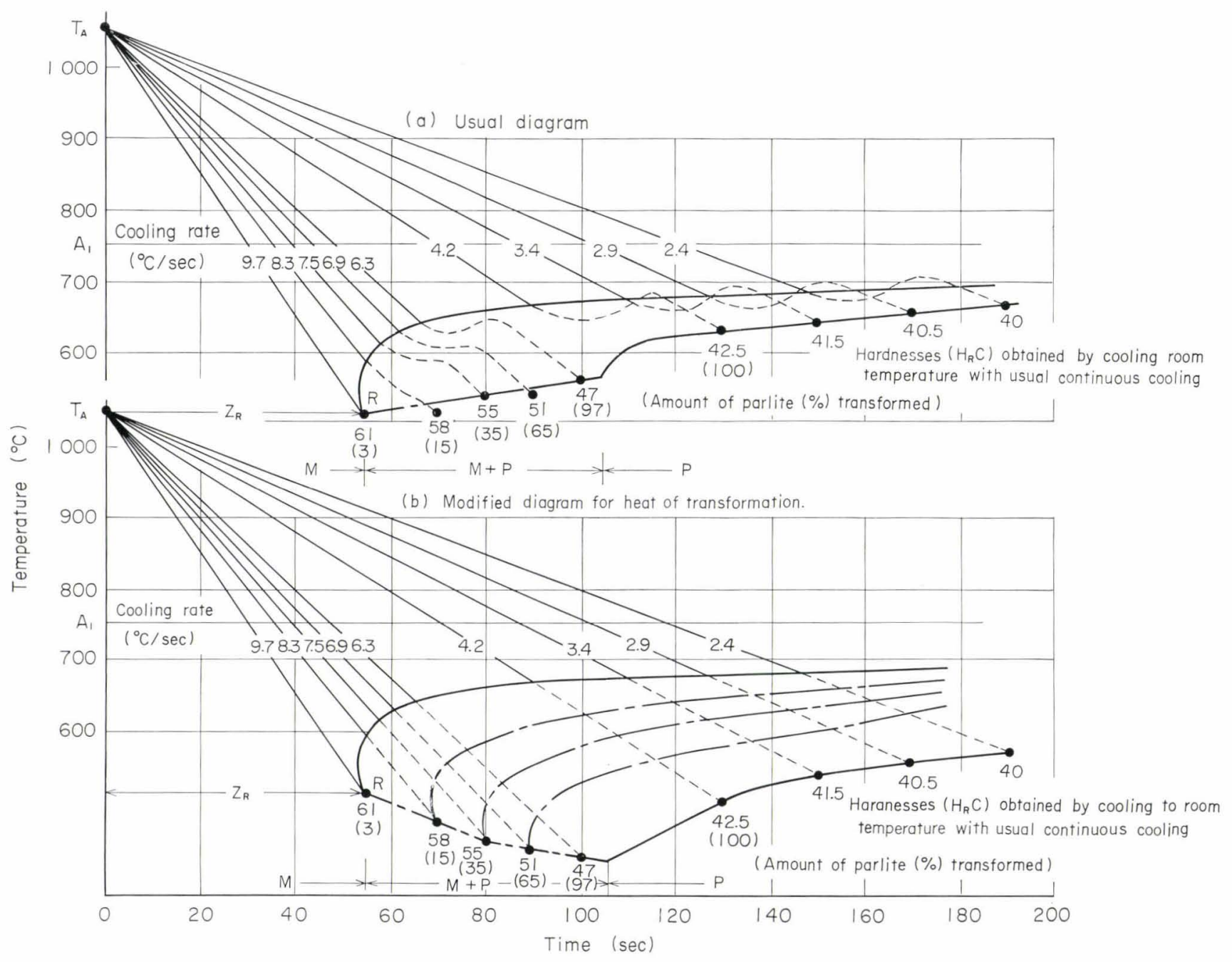

Fig. 6. Continuous cooling transformation diagram of steel used, austenitized at $1050^{\circ} \mathrm{C}$ for $15 \mathrm{~min}$

3. Relation between Transformation Behavior after a Change in Cooling Rate and the CCT Diagram

In Fig. 7 (a), for example, a hardness of $H_{R} C 56$ is obtained when cooling rate is changed from $\alpha$ $\left(3.4^{\circ} \mathrm{C} / \mathrm{sec}\right)$ to $\beta\left(9.7^{\circ} \mathrm{C} / \mathrm{sec}\right)$ at $D$. This hardness corresponds to that obtained when the specimen is cooled at the rate of about $7.8^{\circ} \mathrm{C} / \mathrm{sec}$ without any change in cooling rate (see Fig. 6). A line is drawn from the point at which the cooling line of $7.8^{\circ} \mathrm{C} / \mathrm{sec}$ showing the same hardness of $H_{R} C 56$ passes on the transformation stop or completion line of the CCT diagram, in parallel with the cooling line after the cooling rate has been changed at $D$ (shown by the dotted line), and its intersection with the line $T_{A}-$ $T_{X}$ is indicated by $D^{\prime}$. Then, the transformation behavior when the cooling rate is changed at $D$, is approximately shown by the CCT diagram as if the specimen was cooled at the rate of $\beta$ from $D^{\prime}$. Similarly the points $A^{\prime}, B^{\prime}, C^{\prime}, \ldots$ are determined from the points $A, B, C, \ldots$ at which the cooling rate is changed. However, it is fairly difficult to determine these points $A^{\prime}, B^{\prime}, C^{\prime}, \ldots$ corresponding to $A, B, C, \ldots$, on account of the transformation heat. Therefore, the CCT diagram is modified as shown in Fig. 7 (b) so that the corresponding points $A^{\prime}, B^{\prime}, C^{\prime}, \ldots$ can be readily determined. The study hereafter will be done with the modified CCT diagram which permits an easy analysis.

In order to find easier the location of the points $A^{\prime}, B^{\prime}, C^{\prime}, \ldots$ in the CCT diagram, a curve is defined as I.P. curve (curve of incubation-period consumption) given by tracing the points determined in combination by the temperature at the points $A, B, C, \ldots$ and the time from $T_{A}$ to respective points $A^{\prime}, B^{\prime}$, $C^{\prime}, \ldots$, in a coordinate. This is, however, limited in that the points $A, B, C, \ldots$ are within the temperature range down to the transformation start curve, because the incubation period has been entirely consumed when the transformation starts.

In Figs. 6 and 7, the point where the cooling line from $T_{A}$ at the critical cooling rate $(\gamma)$ reaches the transformation start line, is indicated by $R$, and the time required is indicated by $Z_{R}$. Then, $R$ corresponds to the nose of the CCT curve and $Z_{R}$ to the incubation period in the cooling at the critical cooling rate.

\section{Consumption of Incubation Period during Continuous Cooling}

\section{Consumption of Incubation Period}

The time until the transformation begins during isothermal holding at various temperatures was deter- 


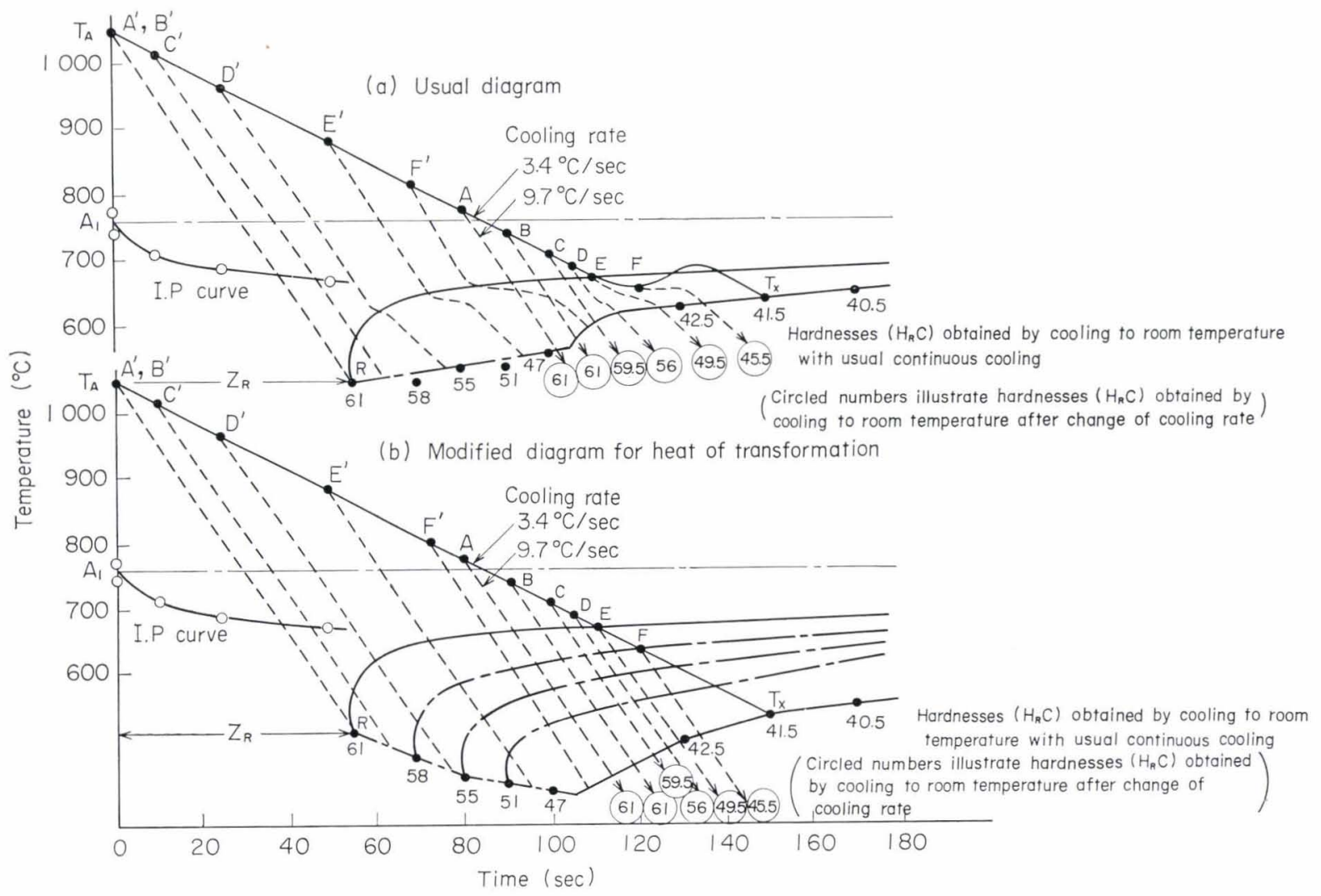

Fig. 7. CCT diagram and transformation behavior after discontinuous change of cooling rate at several points of $A, B, C \ldots$ during continuous cooling from $T_{A}$ to $T_{X}$, austenitized at $1050^{\circ} \mathrm{C}$

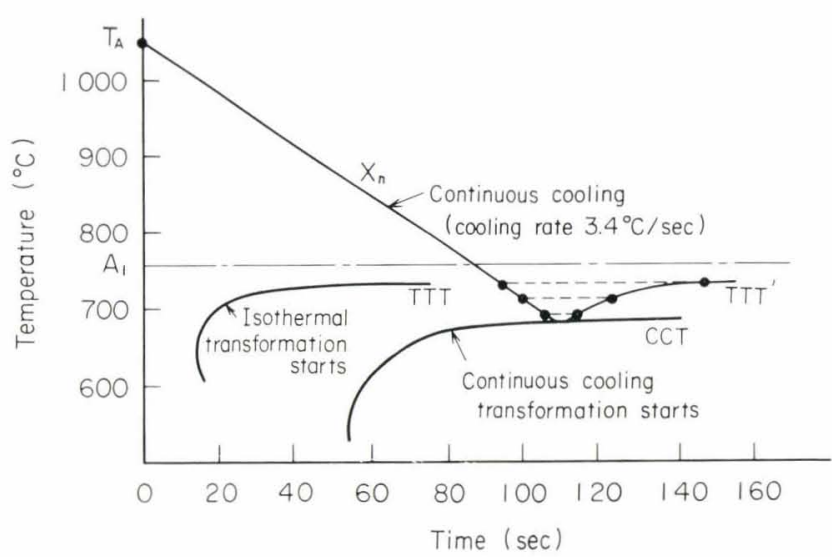

Fig. 8. Transformation starting time (TTT') during isothermal holding at various temperatures after continuous cooling $\left(X_{n}\right)$

mined on the specimen of SUJ 2 which had been austenitized under the same condition (at $1050^{\circ} \mathrm{C}$ for $15 \mathrm{~min}$ ) as the CCT diagram in Fig. 6, and is shown by the symbol TTT in Fig. 8 . The time from $T_{A}$ to the start of transformation in continuous cooling at a rate of $3.4^{\circ} \mathrm{C} / \mathrm{sec}$ was determined on the specimen. After that, the specimen was cooled at the rate of $3.4^{\circ} \mathrm{C} / \mathrm{sec}$ from $T_{A}$ to various temperatures $\left(T_{n}\right)$ for a period of $X_{n}$ and then was isothermally held at the temperature $\left(\mathcal{T}_{n}\right)$. The transformation start line was determined as shown in Fig. 8 by 'TTT'. The experimental results are shown in Table 2.

Assuming that the rate of incubation-period con-
Table 2. Consumption of incubation period at various temperatures during continuous cooling at a rate of $3.4^{\circ} \mathrm{C} / \mathrm{sec}$

\begin{tabular}{c|cccc}
\hline $\begin{array}{c}T_{n} \\
\left(\begin{array}{c}\text { Temp. } \\
\left({ }^{\circ} \mathrm{C}\right)\end{array}\right.\end{array}$ & $\begin{array}{c}\text { TTT } \\
(\mathrm{sec})\end{array}$ & $\begin{array}{c}X_{n} \\
(\mathrm{sec})\end{array}$ & $\begin{array}{c}\mathrm{TTT}^{\prime} \\
(\mathrm{sec})\end{array}$ & I.P. \\
\hline 730 & 60 & 95 & 150 & 0.08 \\
710 & 28 & 100 & 123 & 0.18 \\
690 & 21 & 105 & 115 & 0.52 \\
675 & 18 & 110 & 110 & 1.0 \\
\hline
\end{tabular}

TTT: Isothermal transformation starting time

$X_{n}$ : Continuous cooling time from austenitizing temperature

TTT': Transformation starting time during isothermal holding at various temperatures after continuous cooling

I.P. : Consumption degree of incubation period

sumption is constant during isothermal holding at a temperature, the degree of incubation-period consumption (I.P.) during the cooling from $T_{A}$ to $T_{n}$ can be illustrated as:

$$
\text { I.P. }\left(\mathcal{T}_{n}\right)=\frac{\text { TTT }^{\prime}-\left(\text { TTT }^{\prime}-X_{n}\right)}{\text { TTT }^{\prime}}
$$

where, I.P. $\leqq 1$.

From Eq. (8), the degree of incubation-period consumption by cooling to each temperature at the rate of $3.4^{\circ} \mathrm{C} / \mathrm{sec}$ is obtained as shown in Table 2 .

The degree of incubation-period consumption during continuous cooling at a rate of $3.4^{\circ} \mathrm{C} / \mathrm{sec}$ can 
Table 3. Consumption degree of incubation period calculated by $E$, Scheil's equation (2) at various temperatures during continuous cooling at a rate of $3.4^{\circ} \mathrm{C} / \sec$ (refer to Fig. 1)

\begin{tabular}{c|c|c|c}
$\begin{array}{c}\text { Temp. } \\
\left({ }^{\circ} \mathrm{C}\right)\end{array}$ & $\begin{array}{c}\text { Nucleation } \\
\text { time } \\
Z(T) \\
(\mathrm{sec})\end{array}$ & $\begin{array}{c}d X / d T \\
Z(T)\end{array}$ & $\begin{array}{c}\text { Consumption } \\
\text { degree of incu- } \\
\text { bation period } \\
(\text { I.P. })\end{array}$ \\
\hline 750 & 2400 & & \\
740 & 100 & 0.03 & 0.03 \\
730 & 60 & 0.05 & 0.08 \\
720 & 35 & 0.08 & 0.16 \\
710 & 28 & 0.11 & 0.27 \\
700 & 22 & 0.13 & 0.40 \\
690 & 20 & 0.15 & 0.55 \\
680 & 18 & 0.16 & 0.71 \\
670 & 17 & 0.17 & 0.89 \\
\hline
\end{tabular}

$d X=2.95 \mathrm{sec}, d \mathrm{~T}=10^{\circ} \mathrm{C}$

be calculated graphically by use of Eq. (2) and by dividing into sections of every $10^{\circ} \mathrm{C}$. The result is shown in Table $3 . Z(T)$, in the table, represents the time when isothermal transformation starts at each holding temperature.

\section{Correspondence to CGT Diagram}

If the I.P. curves shown in Fig. 7, in Table 2, and in Table 3 are put together, they exhibit a fairly close agreement with each other, as shown in Fig. 9, so that the I.P. curve defined in Fig. 7 represents the aspect of incubation-period consumption in continuous cooling when $Z_{R}$ is regarded as unity.

If, in the CCT diagram of Fig. 7, the time to reach just the transformation start line by cooling at the critical cooling rate of $9.7^{\circ} \mathrm{C} / \mathrm{sec}$ is indicated by $Z_{R}$, and if the time from $T_{A}$ to each point of $A^{\prime}, B^{\prime}, C^{\prime} \ldots$ is indicated by $Z_{A^{\prime}}, Z_{B^{\prime}}, Z_{C^{\prime}} \ldots$, respectively, $Z_{A^{\prime}}$ $Z_{R}, Z_{B^{\prime}}\left|Z_{R}, Z_{C^{\prime}}\right| Z_{R} \ldots$ will be found to be the degree of incubation period consumed until each point of $A, B, C, \ldots$ on the course of continuous cooling from $T_{A}$ to $T_{X}$. On the other hand, for the point of $F$ at which the transformation has progressed somewhat, the point at a position on the transformation stop line showing the same amount of transformation as at $F$ is considered. The time on abscissa $\left(Z_{F^{\prime}}\right)$ at $F^{\prime}$ on the line of $T_{A}-F$ is the same as the position on the transformation line.

In Fig. 10, $T_{A}-X$ is a cooling curve at a constant rate of $\alpha^{\circ} \mathrm{C} / \mathrm{sec}$. During the cooling process, the cooling rate is discontinuously changed from $\alpha$ to $\beta^{\circ} \mathrm{C} / \mathrm{sec}$ at a point such as $A, B$ or $C$. The transformation behavior after the change of cooling rate cannot be explained by the CCT diagram. However, if the incubation period is taken into consideration, it will be possible to explain the behavior by the CCT diagram itself.

First, the degree of consumed incubation period during cooling at the cooling rate $\alpha$ from $T_{A}$ to several temperatures, is calculated by Eq. (2) (refer to the method for Table 3). The degree of consumption is plotted against temperature as shown in Fig. 10. The abscissa is so scaled with respect to the

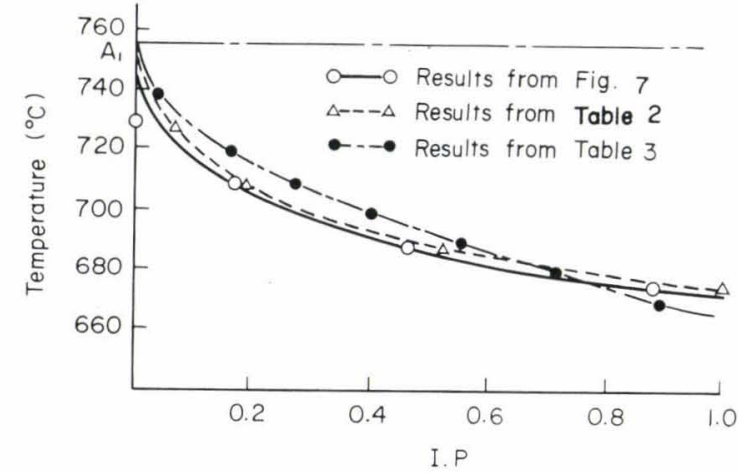

Fig. 9. Consumption degree of incubation period during continuous cooling at a rate of $3.4^{\circ} \mathrm{C} / \mathrm{sec}$

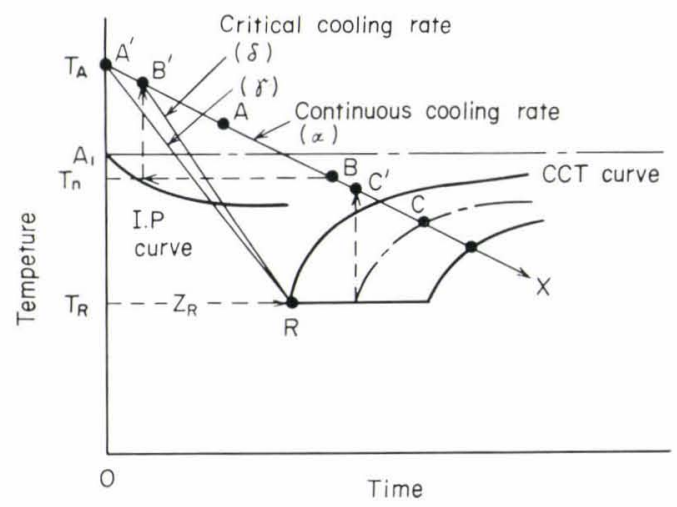

Fig. 10. Schematic diagram showing a method to find transformation behavior and critical cooling rate when the cooling rate is altered during the continuous cooling

degree of incubation-period consumption that the time of $Z_{R}$ will be unity. This curve is called I.P. curve.

Since $A$ is above $A_{1}$, the value of I.P. at $A$ is zero; accordingly, the point $A^{\prime}$ agrees with $T_{A}$ in the position. Draw a horizontal line from $B$, where the cooling rate is changed, and, in turn, a vertical line from the intersection of the horizontal line with the I.P. curve, then the intersection of the vertical line with the line $T_{A}-X$ will give the point $B^{\prime}$. With respect to $C$, at which transformation has progressed somewhat, a vertical line from the point in the transformation stop line showing the same degree of transformation as at $C$, will give the point $C^{\prime}$ at its intersection with the line $T_{A}-X$. If the points $A^{\prime}, B^{\prime}$ and $C^{\prime}$ are determined and if the cooling lines are drawn from $A^{\prime}, B^{\prime}$ and $C^{\prime}$ in parallel with the cooling line of the cooling rate $(\beta)$, the transformation behavior will be estimated from the original CCT diagram.

\section{Critical Cooling Rate}

In Fig. 10, the critical cooling rate $\left(\gamma^{\circ} \mathrm{C} / \mathrm{sec}\right)$ by continuous cooling from $T_{A}$ is indicated by $T_{A}-R$. $R$ corresponds to the nose of the CCT diagram, and its temperature is $T_{R}$. The critical cooling rate from the point $A$ or $B$ is indicated by the slope of $A^{\prime}-R$ or $B^{\prime}-R$, respectively. At the point $B$, which is below $A_{1}$, since some of incubation period has been consumed, the critical cooling rate $(\delta)$ is higher than $\gamma$. 
From equation (7), if $\alpha<\gamma, \delta>\gamma$, and if $\alpha>\gamma$, $\delta<\gamma$. This knowledge will be useful for determining the critical cooling rate from the intermediate temperature in a heat treating process such as stepped quenching or interrupted quenching. In a case of $\alpha<\gamma, \delta$ approaches infinity as

$$
\frac{1}{\alpha} \int_{A_{1}}^{T_{n}} \frac{d T}{Z(T)}
$$

approaches unity. Thus, as the degree of consumed incubation period increases, the critical cooling rate thereafter increases, and reaches infinity when incubation period has been just entirely consumed.

\section{Transformation Behavior in Cooling after Isothermal Holding}

The transformation behavior of the specimen was investigated by the treatment which consisted of austenitizing at $1050^{\circ} \mathrm{C}$ for $15 \mathrm{~min}$, quenching into a lead bath at a temperature of $740^{\circ}, 700^{\circ}, 660^{\circ}$ or $620^{\circ} \mathrm{C}$, isothermal holding at each temperature until the degree of incubation-period consumption reached to $0.25,0.5,0.75$ or 1.0 , and cooling at the rate of $9.7^{\circ} \mathrm{C} / \mathrm{sec}$ to room temperature. The measured hardness $\left(H_{R} C\right)$ are shown in Table 4 .

With the time of isothermal holding at one of the temperatures listed above, the incubation period is consumed, the hardness is decreased, and the amount of pearlitic transformation is increased after the following cooling at $9.7^{\circ} \mathrm{C} / \mathrm{sec}$ to room temperature. At the same degree of incubation-period consumption, the hardness is higher and the amount of pearlitic transformation is smaller with decrease in the tem- perature of isothermal holding. Thus, it is noticed that, with the degree of incubation-period consumption and with decrease in the temperature of isothermal holding, the transformation behavior during the following cooling even at the same cooling rate is altered.

The CCT diagram in Fig. 6 (b) is modified into a CCT $\left(A_{1}\right)$ diagram as shown in Fig. 11, in which the cooling time is counted from $A_{1}$. When the specimen has been cooled at a rate of $9.7^{\circ} \mathrm{C} / \mathrm{sec}$ to room temperature after consuming 0.25 of the incubation period at $740^{\circ} \mathrm{C}$, the hardness is $H_{R} C 58.5$ from Table 5. From Fig. 11, the degree of 0.25 in consumed incubation period corresponds to $25 \mathrm{sec}$ of isothermal holding at $740^{\circ} \mathrm{C}$, because the incubation period at $740^{\circ} \mathrm{C}$ is $100 \mathrm{sec}$. A line is drawn in the CGT $\left(A_{1}\right)$ diagram from a point showing the same hardness of $H_{R} C 58.5$ on the transformation stop or completion line in parallel with the cooling line at

Table 4. Hardness $\left(H_{R} C\right)$ obtained by cooling at a rate of $9.7^{\circ} \mathrm{C} / \mathrm{sec}$ after consumption of incubationperiod in various degree during isothermal holding at various temperatures

\begin{tabular}{c|llll}
\hline I.P. & & & & \\
\hline $\begin{array}{c}\text { Temp. } \\
\left({ }^{\circ} \mathrm{C}\right)\end{array}$ & 0.25 & 0.5 & 0.75 & 1.0 \\
\hline 740 & 58.5 & 55 & 51 & 47 \\
700 & 60.5 & 58 & 54 & 50 \\
660 & 61.5 & 60 & 56 & 52.5 \\
620 & 61.5 & 61.5 & 59.5 & 56 \\
\end{tabular}

I.P. : Consumption degree of incubation period

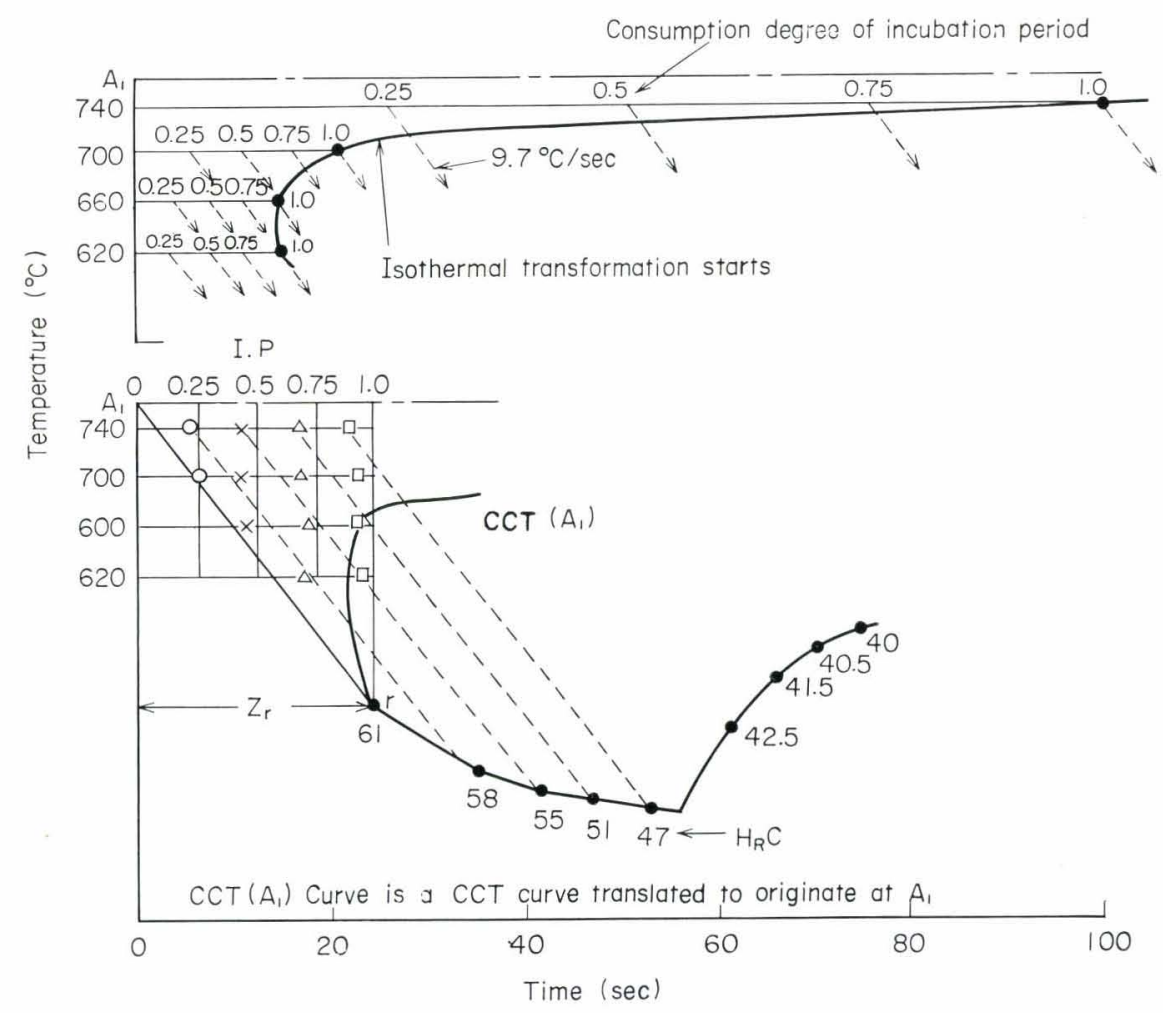

Fig. 11. Cooling transformation behavior after partial consumption of incubation period during isothermal holding at various temperatures, austenitized at $1050^{\circ} \mathrm{C}$ 
Table 5. Hardnesses when the incubation-period of specimen in austenite state was consumed in the same degree by both ways continuous cooling to and isothermal holding at the same temperature and then the specimens were cooled by $9.7^{\circ} \mathrm{C} / \mathrm{sec}$

\begin{tabular}{c|c|c|c}
\hline $\begin{array}{c}\text { Temp. } \\
\left({ }^{\circ} \mathrm{C}\right)\end{array}$ & $\begin{array}{c}\text { Consumption } \\
\text { degree of } \\
\text { incubation- } \\
\text { period }\end{array}$ & $\begin{array}{c}\text { Continuous } \\
\text { cooling } \\
H_{R} C\end{array}$ & $\begin{array}{c}\text { Isothermal } \\
\text { holding } \\
H_{R} C\end{array}$ \\
\hline 710 & 0.18 & 59.5 & 61.0 \\
690 & 0.52 & 56.0 & 56.5 \\
675 & 1.0 & 49.5 & 49.5 \\
\hline
\end{tabular}

the rate of $9.7^{\circ} \mathrm{C} / \mathrm{sec}$, and the intersection of the line with the isothermal holding line at $740^{\circ} \mathrm{C}$ is marked by $\bigcirc$. In each case of cooling at the rate of $9.7^{\circ} \mathrm{C} / \mathrm{sec}$ after the incubation period has been consumed at $740^{\circ} \mathrm{C}$ to a degree of $0.5,0.75$ or 1.0 , such a point is also determined in the same manner with the mark $\times, \triangle$ or $\square$, respectively. Further, in each case where the isothermal holding temperature is $700^{\circ}, 660^{\circ}$ or $620^{\circ} \mathrm{C}$, similar points are determined likewise with marks $\odot, \times, \triangle$ and $\square$ in accordance with the amounts of consumed incubation period of $0.25,0.5,0.75$ and 1.0 . These points marked by $\circ, \times, \triangle$ and $\square$ well agree with the points for degree of consumption of $0.25,0.5,0.75$ and 1.0 , respectively, based on $Z_{r}=1 \quad(\mathrm{I} . \mathrm{P} .=1)$ in their positions on each isothermal line at $740^{\circ}, 700^{\circ}, 660^{\circ}$ or $620^{\circ} \mathrm{C}$. By these results, the assumption in equation (8) that the rate of incubation-period consumption is constant during isothermal holding at a temperature is considered acceptable.

\section{Relation between Incubation-period Consumption by Con- tinuous Cooling and by Isothermal Holding}

Table 5 shows the results of the transformation behavior (expressed by hardness $H_{R} C$ ) when the specimen has been cooled to room temperature at the same rate of $9.7^{\circ} \mathrm{C} / \mathrm{sec}$ after the same degree of incubationperiod consumption attained either by continuous cooling or by isothermal holding.

From these results, it is evident that, if there was no difference in the degree of consumed incubationperiod by either continuous cooling or isothermal holding, the following cooling from the same temperature at the same rate leads to the same transformation behavior. The same degree of incubation-period consumption gives the same effect on the transforma- tion behavior in the cooling from the same temperature, even if there is a difference in the manner of consumption.

\section{Conclusions}

When the cooling rate was changed discontinuously during continuous cooling, the pearlitic transformation behavior of steel and its relation to the CCT diagram were studied. The transformation behavior during cooling after a consumption of incubationperiod by isothermal holding was also investigated. The results obtained are summarized as follows :

(1) The transformation behavior after the cooling rate is changed at a point during continuous cooling is related to the amount of incubation-period consumed or, if on the way of transformation, to the amount of transformation occurred till the change of cooling rate. The behavior shows a considerable difference from that shown by the CCT diagram.

(2) How to estimate the transformation behavior after a change of cooling rate from the CCT diagram is proposed.

(3) The critical cooling rate from a point on a continuous cooling is increased as the degree of consumed incubation-period increases.

(4) The transformation behavior and the critical cooling rate from a point where a degree of incubation-period has been consumed by isothermal holding are related to the degree of incubation-period consumption and the temperature of isothermal holding.

(5) If there is no difference in the degree of consumed incubation-period and in the temperature at the same time, the same influence is given on the transformation behavior thereafter.

\section{REFERENCES}

1) C. A. Liedholm: Trans. ASM, 38 (1947), 180.

2) C.L.M. Cottrel: JISI, 175 (1954), 273.

3) A. Rose and W. Peter: Stahl u. Eisen, 72 (1952), 1063.

4) W. Steven and G. Mayer: JISI, 174 (1953), 33.

5) R. A. Grange and J. M. Kiefer: Trans. ASM, 29 (1941), 85.

6) G. K. Manning and C. H. Lorig: Trans. AIME, 167 (1946), 442 .

7) W. I. Pumphrey and F. W. Jones: JISI, 159 (1948), 137.

8) E. Scheil: Arch. Eisenhüttenw., 12 (1935), 565.

9) N. Shimizu and I. Tamura: Tetsu-to-Hagané, 61 (1975), 3129 and Trans. ISIJ, 16 (1976), 655.

10) Max Plank Inst.: Atlas zur Wärmebehandlung der Stähle, Eisenforsch, (1954), II-225D. 